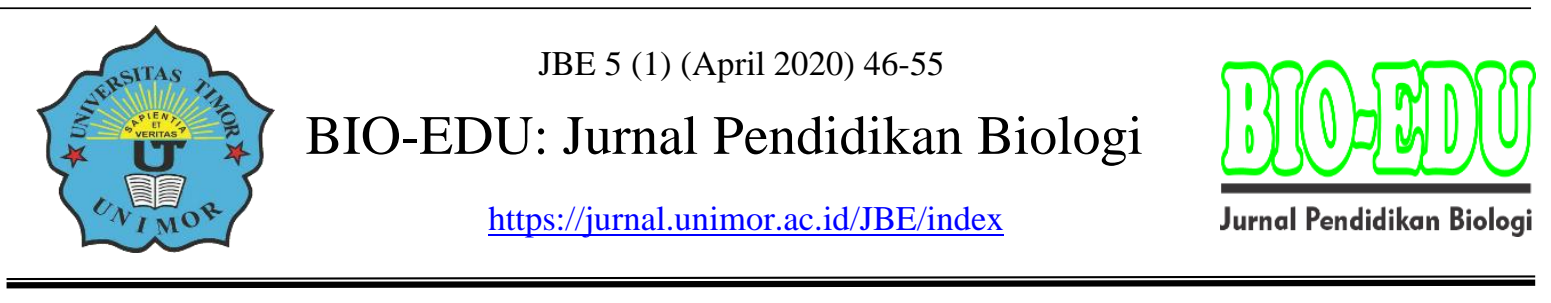

\title{
Preferensi Pakan Ikan Tongkol (Euthynnus affinis) di Perairan Pantai Utara Timor Tengah Utara
}

\author{
Agustinus Binsasi \\ Fakultas Ilmu Pendidikan, Universitas Timor, Kefamenanu, TTU - NTT, 85613, Indonesia \\ Email: binsasiagustinus@yahoo.com
}

DOI: $\underline{\text { https://doi.org/10.32938/ jbe.v5i1.530 }}$

\begin{abstract}
Abstrak
Ikan tongkol (Euthynnus affinis) merupakan salah satu sumberdaya perikanan yang terdapat di perairan Pantai Utara, Kabupaten Timor Tengah Utara. Pola pemanfaatan yang bersifat eksploratif dikhawatirkan akan mempengaruhi jumlah populasi ikan tersebut di Pantai Utara. Dikhawatirkan pada masa yang akan datang kehidupan ikan tongkol akan terancam, baik berupa kepunahan maupun degradasi genetis. Untuk mencegah punahnya spesies ikan yang masih ada di Pantai Utara tersebut dibutuhkan suatu upaya pelestarian melalui pengelolaan dan pelestarian ikan tongkol secara terpadu, dengan memperhatikan aspek penangkapan, habitat, dan budidaya agar potensinya dapat dimanfaatkan secara optimal dan lestari. Untuk mendukung kegiatan pengelolaan ikan tongkol di perairan Pantai Utara, Kabupaten Timor Tengah Utara diperlukan informasi diantaranya aspek-aspek biologi dan ekologi. Salah satu aspek biologi yang perlu dikaji adalah preferensipakan ikan tongkol. Penelitian ini dilaksanakan pada Bulan Januari- April 2016, di Temkuna Kelurahan Humusu Wini Kecamatan Insana Utara Kabupaten Timor Tengah Utara. Metode dalam penelitian ini adalah metode survey. Penelitian ini bertujuan untuk mengetahui preferensi pakan ikan tongkol (Euthynnus affinis) di perairan Pantai Utara Timor Tengah Utara. Pengambilan sampel menggunakan metode acak sederhana (simple random sampling). Jumlah sampel ikan yang diambil sebanyak 10\% dari total hasil tangkapan nelayan. Analisis laboratorium dilakukan di Laboratorium Biologi Fakultas Ilmu Pendidikan (FIP) Universitas Timor. Analisis data meliputi panjang dan berat total, panjang usus relatif, frekuensi kejadian, dan indeks bagian terbesar. Jumlah ikan tongkol (Euthynnus affinis) yang diamati selama penelitian adalah sebanyak 180 ekor, terdiri dari 108 ekor makanannya adalah ikan-ikan kecil (ikan teri), 55 ekor makanannya adalah udang-udang kecil, dan 17 ekor makanannya adalah ikan teri dan udang-udang kecil dengan panjang total berkisar antara $17-38 \mathrm{~cm}$ dan berat total berkisar antara 49-824 gram. Ikan tongkol (Euthynnus affinis) termasuk ikan karnivora.
\end{abstract}

Kata kunci : Preferensi Pakan; Ikan Tongkol (Euthynnus affinis); Pantai Utara

\section{PENDAHULUAN}

Indonesia merupakan negara kepulauan terbesar di dunia yang terdiri dari 17.508 pulau dengan panjang garis pantai lebih dari $81.000 \mathrm{~km}$. Wilayah pesisir dan lautan Indonesia juga dikenal sebagai negara dengan kekayaan dan keanekaragaman hayati (biodiversity) laut terbesar di dunia dengan memiliki ekosistem pesisir seperti mangrove, terumbu karang dan padang lamun. Sumberdaya perikanan di Indonesia sangat melimpah, tetapi pengolahan dan pemanfaatan serta pengelolaannya untuk memperoleh manfaat 
ekonomi yang optimal sampai saat ini masih belum maksimal dibandingkan dengan potensi yang ada. Sumberdaya perikanan merupakan salah satu sumberdaya alam yang bersifat open access yaitu pengambilannya secara terbuka dan bebas, tidak dibatasi dan sering kali disebut sumberdaya milik bersama. Perikanan tangkap adalah usaha ekonomi dengan mendayagunakan sumberdaya hayati perairan dan alat tangkap untuk menghasilkan ikan dan memenuhi permintaan ikan. Kegiatan penangkapan ikan yang tidak diatur bagi nelayan-nelayan setempat dapat mengakibatkan overfishing atau penangkapan berlebih di daerah, penurunan mutu bahkan dapat merusak produktivitasnya (Anggita, 2015).

Preferensi pakan merupakan salah satu informasi penting yang dapat digunakan untuk mengetahui pola dalam upaya mengelola sumberdaya perikanan. Pantai Utara merupakan salah satu daerah perairan laut dibagian utara Kabupaten Timor Tengah Utara, yang terdapat di Kecamatan Insana Utara, Kecamatan Biboki Moenleu dan Kecamatan Biboki Anleu.

Pertumbuhan ikan tongkol yang tidak terkontrol mengakibatkan penurunan populasi ikan lain dalam jangka panjang dan berkaitan erat dengan rantai makanan. Upaya pengelolaan ikan tongkoldapat dilakukan melalui pengendalian populasinya di perairan laut.

Ikan tongkol merupakan bagian dari komunitas perairan laut sehingga upaya pengendaliannya harus berdasarkan pada keseimbangan ekologis. Oleh karena itu, upaya pengendalian ikan tongkol juga harus diselaraskan dengan upaya pengendalian populasi ikan lain sampai terjadi keseimbangan ekologis. Pelaksanaan pengelolaan perikanan yang utama bertujuan untuk meningkatkan produktivitas optimum dan melestarikan sumber daya perikanan melalui pengelolaan secara optimal. Langkah-langkah pengelolaan secara optimal dapat dilaksanakan dengan pengumpulan data/monitoring terus-menerus melalui sampling hasil tangkapan guna mencatat komposisi spesies, komposisi panjang dan berat, beberapa aspek reproduksi, otolit maupun isi saluran pencernaan (Nikolsky, 1980; Sukadi, 1996).

Preferensi adalah pilihan, kecenderungan, dan kesukaan. Preferensi pakan meliputi panjang relatif saluran pencernaan dan tingkat kesukaan makan. Preferensi pakan memberikan gambaran mengenai komposisi pakan, kebiasaan makan (food habits) dan tingkat kesukaan ikan tongkol terhadap jenis pakan tertentu. Kebiasaan makan ikan tongkol menunjukkan hubungan interaksi antara ikan dengan lingkungannya, seperti mangsa pemangsa, persaingan dan tingkatan trofik melalui rantai makanan. Informasi jenis pakan dan food habits sangat penting dalam upaya pengelolaan sumber daya ikan untuk mencapai keseimbangan ekosistem luat di masa mendatang. Penelitian preferensi pakan ikan tongkol (Euthynnus affinis) sangat perlu dilakukan dalam rangka menyeimbangkan ekosistem laut sehingga kelestarian sumber daya ikan tetap terjaga dan produktivitas penangkapan dapat mencapai tingkat optimal (Ariasari, 2014).

Rumusan masalah pada penelitian ini adalah : 1) Apa jenis preferensi pakan ikan tongkol (Euthynnus affinis)?, 2) Bagaimana pola makan pada ikan tongkol (Euthynnus affinis)?, 3) Bagaimana cara mengimplementasikannya dalam proses pembelajaran di sekolah?

Tujuan dari penelitian ini adalah : 1) Untuk mengetahui komposisi jenis pakan pada ikan tongkol (Euthynnus affinis), 2) Untuk mengetahui kebiasaan makan (food habits), dan 
preferensi pakan ikan Tongkol (Euthynnus affinis) diperairan Pantai Utara Timor Tengah Utara, 3) Untuk diimplementasikan dalam proses pembelajaran di sekolah.

Manfaat dari penelitian ini adalah : 1) Sebagai bahan kajian untuk populasi ikan di Pantai Utara Timor Tengah Utara, terutama ekobiologi ikan tongkol (Euthynnus affinis) masih sangat jarang dilakukan, 2) Sebagai sumber data dan informasi yang bermanfaat serta berkelanjutan terhadap perkembangan ikan tongkol dalam rangka menentukan formulasi alternatif strategi pemanfaatan sumber daya ikan tongkol (Euthynnus affinis) diperairan Pantai Utara Timor Tengah Utara, 3) Sebagai salah satu bentuk implementasi dari pengetahuan biologi terutama bidang zoologi vertebrata dan struktur perkembangan hewan.

\section{METODE}

\section{Waktu dan Tempat}

Penelitian dilakukan di Laut Pantai Utara, Temkuna Desa Humusu Wini, Kecamatan Insana Utara, Kabupaten Timor Tengah Utara dan Laboratorium Biologi Universitas Timor dari Januari - April 2016.

\section{Alat dan Bahan}

Tabel 1. Alat yang digunakan selama penelitian

\begin{tabular}{|c|c|c|}
\hline NamaAlat & Spesifikasi & Fungsi \\
\hline Jaring insang & $\begin{array}{l}\text { Mesh Size } 1 \text { inchi, 1,5 inchi, } 2 \\
\text { inchi }\end{array}$ & $\begin{array}{l}\text { Menangkap ikan sampel hasil } \\
\text { tangkapan }\end{array}$ \\
\hline $\begin{array}{l}\text { Timbangan } \\
\text { digital }\end{array}$ & $\begin{array}{l}\text { Shimadzu BX 320D tingkat } \\
\text { ketelitian 0,1g }\end{array}$ & $\begin{array}{l}\text { Mengukur berat total tubuh } \\
\text { ikan sampel. }\end{array}$ \\
\hline Penggaris & Butterfly tingkat ketelitian $0,1 \mathrm{~cm}$ & $\begin{array}{l}\text { Mengukur panjang total tubuh } \\
\text { ikan sampel. }\end{array}$ \\
\hline Dissecting kit & $\begin{array}{l}\text { Japan stainless (Pinset), Crown } \\
\text { stainless (Gunting) }\end{array}$ & $\begin{array}{l}\text { Gunting : memotong perut } \\
\text { dan saluran pencernaanikan } \\
\text { Pinset : mengambil saluran } \\
\text { pencernaan ikan } \\
\text { Scalpel : mengeluarkan isi } \\
\text { saluran pencernaan ikan }\end{array}$ \\
\hline Mikroskop & $\begin{array}{l}\text { Olympus CX } 21 \\
\text { Perbesaran 4x, 10x }\end{array}$ & $\begin{array}{l}\text { Mengamati isi saluran } \\
\text { pencernaan ikan sampel. }\end{array}$ \\
\hline Cawan petri & Pyrex & $\begin{array}{l}\text { Wadah isi saluran } \\
\text { pencernaan. }\end{array}$ \\
\hline Botol film & Bervolume $20 \mathrm{ml}$ & $\begin{array}{l}\text { Tempat saluran pencernaan } \\
\text { yang telah diawetkan. }\end{array}$ \\
\hline Cool box & Marine cooler & $\begin{array}{l}\text { Tempat ikan sampel hasil } \\
\text { tangkapan. }\end{array}$ \\
\hline Kertas label & Ukuran $1 \times 2 \mathrm{~cm}$ & Etiket keterangan sampel. \\
\hline Pipettetes & PyrexVolume $1 \mathrm{ml}$ & $\begin{array}{l}\text { Mengambil isi makanan yang } \\
\text { telah diencerkan. }\end{array}$ \\
\hline
\end{tabular}




\begin{tabular}{lll}
\hline $\begin{array}{l}\text { Wadah } \\
\text { plastic }\end{array}$ & Lion Star Volume 3000 $\mathrm{ml}$ & $\begin{array}{l}\text { Wadah sampel ikan pada saat } \\
\text { akan dibedah. }\end{array}$ \\
\hline Freezer & Sharp & $\begin{array}{l}\text { Pendingin ikan sampel yang } \\
\text { akan dibedah. }\end{array}$ \\
\hline Benang jahit & $\begin{array}{l}\text { Panjang disesuaikan dengan } \\
\text { panjang saluran pencernaan }\end{array}$ & $\begin{array}{l}\text { Alat bantu untuk mengukur } \\
\text { panjang saluran pencernaan } \\
\text { ikan sampel. }\end{array}$ \\
\hline Gelasukur & Pyrex Volume $10 \mathrm{ml}$ dan $50 \mathrm{ml}$ & $\begin{array}{l}\text { Mengukur formalin dan } \\
\text { aquades tuntuk pengenceran } \\
\text { larutan }\end{array}$ \\
\hline
\end{tabular}

Tabel 2. Bahan yang digunakan selama penelitian

\begin{tabular}{lcl}
\hline NamaBahan & Spesifikasi & \multicolumn{1}{c}{ Fungsi } \\
\hline Ikan Tongkol & $180 \mathrm{ekor}$ & Ikan sampel penelitian \\
\hline Alkohol 70\% & $1000 \mathrm{ml}$ & $\begin{array}{l}\text { Sebagai cairan pengawet saluran } \\
\text { pencernaan ikan sampel. }\end{array}$ \\
\hline Aquadest & $5000 \mathrm{ml}$ & $\begin{array}{l}\text { Sebagai campuran alkohol agar } \\
\text { konsentrasinya menjadi 4\%. }\end{array}$ \\
\hline Es batu & 18 buah & $\begin{array}{l}\text { Menjaga ikan tetap segar dalam } \\
\text { perjalanan dari pantai utara ke } \\
\text { lab. Biologi unimor. }\end{array}$ \\
\hline
\end{tabular}

\section{Teknik Pengumpulan Data}

Sampel ikan merupakan hasil tangkapan di area perairan laut pantai utara sehingga diharapkan mewakili keseluruhan populasi. Ikan diperoleh dari hasil tangkapan nelayan menggunakan jaring insang/pukat yang dipasang pada sore hari dan diangkat pada pagi hari. Penentuan titik pengambilan sampel berpindah-pindah tempat dan tersebar di seluruh perairan laut pantura. Sampel ikan diambil secara acak sebanyak 10\% dari hasil tangkapan nelayan setiap bulan. Sampel ikan merupakan ikan tongkol (Euthynnus affinis). Ikan hasil tangkapan diamati morfologi tubuhnya untuk memastikan sampel ikan penelitian. Ikan tongkol memiliki bibir tebal, elongasi dahi curam. Pengamatan dilakukan di Laboratorium Biologi Universitas Timor. Sampel ikan dimasukkan ke dalam freezer dan diamati pada hari selanjutnya.

Panjang total ikan diukur menggunakan penggaris dan berat ikan diukur menggunakan timbangan. Ikan dibedah untuk menentukan jenis kelaminnya melalui pengamatan gonade dan diambil saluran pencernaannya. Pembedahan dilakukan dengan cara mengiris tepi dubur ikan hingga ke arah atas menuju gurat sisi dan dilanjutkan ke arah depan sampai bagian belakang insang (mengikuti rongga perut). Bagian irisan dapat dilipat ke bawah agar mudah mengeluarkan lambung dan usus. Alat pencernaan dimasukkan ke dalam botol sampel yang terpisah dan ditambahkan formalin $4 \%$. Awetan sampel saluran pencernaan diberi label etiket sesuai dengan waktu pengambilan sampel.

Sampel saluran pencernaan yang diawetkan kemudian diukur panjangnya. Isi lambung dikeluarkan dan diencerkan dengan aquadest. Volume tiap jenis pakan dihitung 
menggunakan sedgwick rafter. Pengamatan jenis pakan menggunakan metode kuantitatif, yakni metode numerik dan metode volumetrik. Metode numerik memperhitungkan komponen jenis-jenis pakan, sedangkan metode gravimetrik menghitung volume tiap-tiap jenis pakan (Zacharia et al., 2013). Pengamatan jenis pakan menggunakan mikroskop perbesaran 4x dan 10x. Identifikasi tiap-tiap jenis pakan menggunakan buku Akihiko Shirota (1996).

\section{Teknik Pengambilan Data} sekali.

Pengambilan sampel dilakukan secara acak dengan metode survei setiap bulan

\section{Analisis Data}

\section{Panjang Usus Relatif}

Analisis panjang usus relatif bertujuan untuk mengetahui tipe makanan ikan melalui perbandingan panjang usus dengan panjang tubuh di dalam bentuk rumus :

$$
\text { Panjang Usus Relatif }=\frac{\text { Panjang Usus }}{\text { Panjang Tubuh }}
$$

Menurut Nikolsky (1963), panjang usus relatif untuk ikan karnivora adalah $<1$, untuk ikan omnivora antara $1-3$, sedangkan untuk ikan herbivora $>3$.

\section{Frekuensi Kejadian}

Frekuensi kejadian ditentukan dengan mencatat keberadaan masing-masing organisme yang terdapat dalam sejumlah alat pencernaan ikan yang berisi bahan makanannya dan dinyatakan dalam persen (Effendie,1979). Frekuensi kejadian pakan dihitung dengan rumus :

$$
\begin{aligned}
& \mathrm{FK}=\frac{\mathrm{Ni}}{\mathrm{I}} \times 100 \% \\
& \text { Keterangan: } \\
& \mathrm{FK}=\text { Frekuensi kejadian } \\
& \mathrm{Ni}=\text { Jumlah total satu jenis organisme } \\
& \mathrm{I} \quad=\text { Total lambung berisi }
\end{aligned}
$$

\section{Indeks Bagian Terbesar}

Indeks bagian terbesar (index of preponderance) merupakan gabungan dari metode frekuensi kejadian dengan metode volumetrik. Indeks bagian terbesar sering digunakan untuk menganalisis kebiasaan makanan ikan dan menilai bermacam-macam makanan yang menjadi kesukaan ikan (Effendie, 1979). Analisis indeks bagian terbesar dihitung dengan rumus:

$\mathrm{IP}=\frac{\mathrm{ViOi}}{\sum_{\mathrm{i}=1}^{\mathrm{n}} \mathrm{VixOi}} x 100$

Keterangan: IP = indeks bagian terbesar (Index of Preponderance)

$\mathrm{Vi}=$ persentase volume makanan ikan jenis ke-i

$\mathrm{Oi} \quad=$ persentase frekuensi kejadian makanan jenis ke-i

$\mathrm{n} \quad=$ jumlah organisme makanan ikan $(\mathrm{i}=1,2,3, \ldots \mathrm{n})$ yakni:

Analisis kebiasaan makanan dibedakan menjadi tiga kategori (Effendie, 1979), 


$$
\begin{array}{ll}
\text { IP }>40 \% & =\text { Makanan utama } \\
4 \% \leq \mathrm{IP} \leq 40 \% & =\text { Makanan pelengkap } \\
\text { IP }<4 \% & =\text { Makanan tambahan }
\end{array}
$$

\section{HASIL DAN PEMBAHASAN}

\section{Hasil}

\section{Sebaran Panjang Tubuh Ikan Tongkol (Euthynnus affinis )}

Total ikan tongkol (Euthynnus affinis) yang tertangkap selama penelitian ini sebanyak 180 ekor yang terdiri dari 108 ekor makanannya adalah ikan-ikan kecil (ikan teri), 55 ekor makanannya adalah udang-udang kecil, dan 17 ekor makanannya adalah ikan teri dan udang-udang kecil. Kisaran panjang total tubuh antara $17-38 \mathrm{~cm}$ yang diukur menggunakan mistar dan berat total berkisar antara 49-824 gram yang diukur menggunakan timbangan. Jumlah ikan terbesar (103 ekor) yang berada pada kelas panjang 20-22 cm, sedangkan jumlah ikan terendah ( 3 ekor) yang berada pada kelas panjang $29-31 \mathrm{~cm}$.

\section{Panjang Usus Relatif}

Panjang usus relatif digunakan untuk mengetahui makanan alami ikan. Panjang usus relatif ikan tongkol (Euthynnus affinis ) di Laut Pantai Utara disajikan pada Gambar 1.

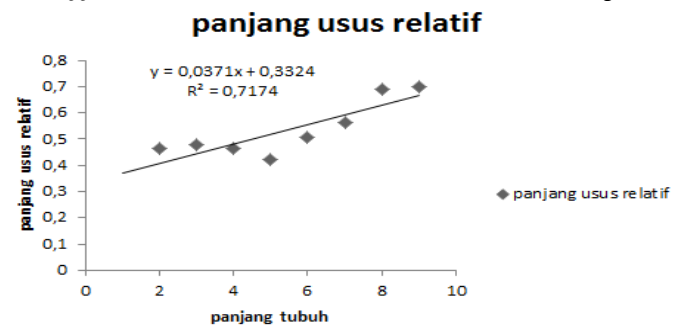

\section{Gambar 1. Panjang Usus Relatif Ikan Tongkol (Euthynnus affinis) di Laut Pantai} Utara Kabupaten TTU

Panjang usus relatif ikan tongkol di Laut Pantai Utara berkisar antara 0,36-0,90 dimana panjang usus relatif terendah terdapat pada kisaran panjang $>27 \mathrm{~cm}$ (rerata 0,42) dan ukuran tertinggi pada kisaran panjang $<20 \mathrm{~cm}$ (rerata 0,47 ).

\section{Frekuensi Kejadian}

Frekuensi Kejadian (FK) makanan ikan tongkol di Laut Pantai Utara Kabupaten TTU memiliki nilai yang berbeda. Perbedaan nilai ini dapat dilihat pada Gambar 2.

frekuensi (\%)

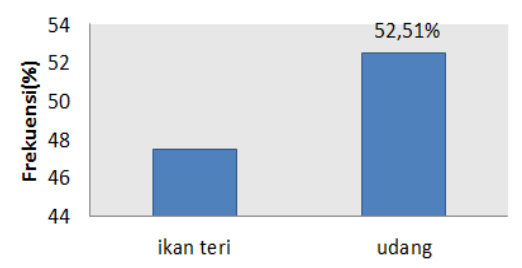

Gambar 2. Frekuensi kejadian jenis makanan ikan tongkol (Euthynnus affinis) di Laut Pantai Utara Kabupaten TTU 
Udang merupakan jenis makanan yang paling banyak ditemukan di Laut Pantai Utara dengan nilai $52,51 \%$ sedangkan jenis makanan lainnya yang ditemukan adalah ikan teri dengan nilai $47,49 \%$.

Indeks Bagian Terbesar (IP)

Ikan memiliki nilai indeks bagian terbesar tertinggi di Laut Pantai Utara Kabupaten TTUyang dapat dilihat pada Tabel 3.

Tabel 3. Indeks Bagian Terbesar (IP) Ikan Tongkol (Euthynnus affinis) di Laut Pantai Utara Kabupaten TTU

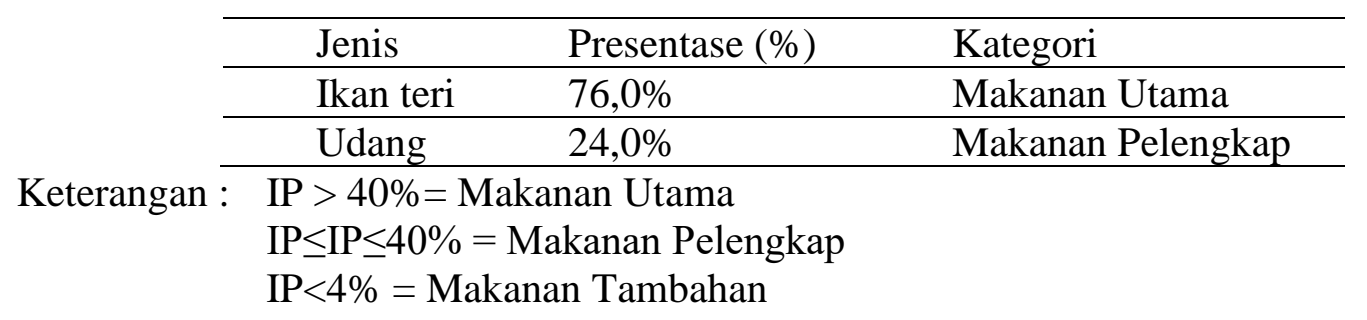

Ikan teri merupakan makanan utama ikan tongkol di Laut Pantai Utara Kabupaten TTU dengan presentasenya sebesar 76,0\% sedangkan udang merupakan makanan pelengkap ikan tongkol di Laut tersebut dengan presentasenya $24,0 \%$.

\section{PEMBAHASAN}

Wilayah perairan pantai utara Timor Tengah Utara memiliki berbagai komoditas agroindustri unggulan dibidang perikanan (tangkap, budidaya, dan pengolahan). Salah satu komoditas perikanan tangkap unggulan adalah ikan tongkol. Pertumbuhan dan perkembangan sumber daya ikan tongkol di suatu perairan tentunya sangat dipengaruhi oleh ketersediaan makanan yang akan digunakan untuk mendukung kehidupan ikan tongkol di perairan tersebut.

Total ikan tongkol (Euthynnus affinis) yang tertangkap pada penelitian ini selama 4 bulan (Januari - April 2016) sebanyak 180 ekor yang terdiri dari 108 ekor makanannya adalah ikan-ikan kecil (ikan teri), 55 ekor makanannya adalah udang-udang kecil, dan 17 ekor makanannya adalah ikan teri dan udang-udang kecil. Kisaran panjang total tubuh antara 17-38 cm yang diukur menggunakan mistar. Jumlah ikan terbesar (103 ekor) yang berada pada kelas panjang 20-22 cm, sedangkan jumlah ikan terendah (3 ekor) yang berada pada kelas panjang $29-31 \mathrm{~cm}$.

Panjang usus relatif digunakan untuk mengetahui makanan alami ikan. Panjang usus relatif ikan tongkol di Laut Pantai Utara berkisar antara 0,36-0,90 dimana panjang usus relatif terendah terdapat pada kisaran panjang $>27 \mathrm{~cm}$ (rerata 0,42) dan ukuran tertinggi pada kisaran panjang $<20 \mathrm{~cm}$ (rerata 0,47 ). Nilai panjang usus relatif yang didapatkan menunjukkan bahwa ikan tongkol termasuk kedalam golongan ikan karnivora, karena memiliki nilai panjang usus relatif <1, seperti yang dinyatakan oleh Nikolsky (1963). Proporsi panjang usus relatif terhadap panjang total tubuh pada ikan karnivora cenderung lebih pendek dari pada ikan herbivora dan omnivora. 
Frekuensi Kejadian(FK) merupakan suatu metode yang menggambarkan intensitas tiap jenis makanan yang ditemukan dalam saluran pencernaan ikan yang dinyatakan dalam persen (\%). Frekuensi Kejadian makanan ikan tongkol di Laut Pantai Utara Kabupaten TTU memiliki nilai yang berbeda. Udang merupakan jenis makanan yang paling banyak ditemukan di Laut Pantai Utara dengan nilai 52,51\% sedangkan jenis makanan lainnya yang ditemukan adalah ikan teri dengan nilai $47,49 \%$.

Indeks bagian terbesar digunakan untuk menilai bermacam-macam makanan yang menjadi kesukaan ikan (Effendie, 1979). Berdasarkan hasil perhitungan indeks bagian terbesar, ditemukan bahwa Ikan teri merupakan makanan utama ikan tongkol di Laut Pantai Utara Kabupaten TTU dengan presentasenya sebesar 76,0\% sedangkan udang merupakan makanan pelengkap ikan tongkol di Laut tersebut dengan presentasenya $24,0 \%$.

\section{Implementasi Hasil Penelitian dalam Pembelajaran di Sekolah}

Implementasi hasil penelitian dalam pembelajaran di sekolah pada bidang biologi sasarannya pada tingkat SMA Kelas X semester II bab 8 tentang Mengenal Dunia Hewan pada sub materi Vertebrata pokok bahasan tentang Ikan (Pisces) dengan standar kompetensi Memahami Manfaat Keanekaragaman Hayati dan kompetensi dasar Mendeskripsikan Ciri-Ciri Filum Dalam Dunia Hewan Dan Peranannya Bagi Kehidupan.

\section{KESIMPULAN DAN SARAN}

\section{Kesimpulan}

Kesimpulan dari penelitian adalah sebagai berikut :

1. Ukuran panjang ikan tongkol (Euthynnus affinis) yang banyak tertangkap adalah pada kisaran ukuran $17-40 \mathrm{~cm}$ yang didominasi oleh selang kelas ukuran panjang $20-22$ cm dengan proporsi 57,22 \% dari total keseluruhan sampel ikantongkol yang diperoleh, sedangkan untuk ukuran berat ikan tongkol (Euthynnus affinis) yang banyak tertangkap berada pada kisaran berat 49 - 824 gram yang didominasi oleh selang kelas berat 49 145 gram dengan proporsi 64,44\% dari total keseluruhan sampel ikan tongkol yang diperoleh.

2. Ikan tongkol (Euthynnus affinis) di perairan pantai uatara Timor Tengah Utara merupakan golongan ikan karnivora.

3. Jenis makanan yang menjadi makanan utama ikan tongkol (Euthynnus affinis) adalah ikan teri dan udang sebagai makanan pelengkap

4. Hasil penelitian dengan judul PREFERENSI PAKAN IKAN TONGKOL (Euthynnus affinis) DI PERAIRAN PANTAI UTARA TIMOR TENGAH UTARA dapat diimplementasikan dalam ilmu biologi terutama pada materi pelajaran di sekolah tingkat SMA yakni materi tentang Mengenal Dunia Hewan pada sub materi Vertebrata pokok bahasan tentang Ikan (Pisces).

\section{Saran}

Saran dari penelitian ini adalah sebagai berikut : 
1. Ikan teri merupakan makanan utama dan udang sebagai makanan pelengkap ikan tongkol (Euthynnus affinis), sehingga untuk menjamin kelestarian sumberdaya ikan tongkol, maka perludilakukan upaya pengelolaan yang tepat seperti pembatasan penangkapan pada ikan teri dan udang sebagai makanan ikan tongkol (Euthynnus affinis).

2. Penelitian lebih lanjut mengenai aspek panjang berat dan faktor kondisi, laju pertumbuhan ikan, dan kajian stok ikan tongkol (Euthynnus affinis) perlu dilakukan di perairan pantai utara Timor Tengah Utara untuk memberikan informasi biologi semakin banyak mengenai ikan tongkol, sehingga dapat digunakan sebagai salah satu dasar pegelolaan perikanan di Kabupaten Timor Tengah Utara.

\section{DAFTAR RUJUKAN}

Ana Ariasari, 2014. Preferensi Pakan Ikan red Devil (Amphilophus Labiatus)Di Waduk Sermo Kabupaten Kulonprogo. Skripsi Fakultas Pertanian Universitas Gadjah MadaYogyakarta. Yogyakarta.

Anggita Yohana, 2015. Komposisi dan Hubungan Panjang-Berat Ikan Hasil Tangkapan Jaring Tarik di Pantai Prigi Kabupaten Trenggalek. Skripsi Fakultas PertanianUniversitas Gadjah MadaYogyakarta. Yogyakarta.

Anakotta, A. R. F. 2002. Studi Kebiasaan Makanan Ikan-Ikan yang Tertangkap di Sekitar Ekosistem Mangrove Pantai Oesapa dan Oebelo Teluk Kupang, Nusa Tenggara Timur. Program Pascasarjana. Institut Pertanian Bogor. Master Thesis.

Anonim. 2016. Preferensi. < http://kbbi.web.id/preferensi>. Diakses 15 Mei 2016.

Anonim. 2016. www.goegle-klasifikasi ikan tongkol.com. Diakses Mei2016.

Caddy, J. F. \& G. D. Sharp. 1986. An Ecological Framework for Marine Fishery Investigations. FAO Fish. Tech. Pap. 283. 152 pp.

Collwell, R.K dan D. J. Futuyama. 1971. On The Measurment of Niche Bredth and Overlap. Ecology. 52 (4): 567-576.

Dalie, A.Z. dan H.A. Rahmadi. 2007. Memilih dan Membuat Pakan Tepat untuk Louhan. Perikanan Agromedia. Yogyakarta.

Djajirah, A.S. 1996. Pakan Ikan Alami. Penerbit Kanisius. Yogyakarta. 17-18 p.

Effendie, M.I. 1979. Metode Biologi Perikanan. Yayasan Dewi Sri. Bogor. 112 p.

Effendie, M.I. 1997. Biologi Perikanan. Yayasan Pustaka Nusantara. Yogyakarta.

Nikolsky, G.V. 1963. The Ecology of Fishes.Translated by: L. Brikett.Academic Press.London and New York.352 p.

Nikolsky, G.V. 1980. Theory of Fish Population Dynamics as The Biological Background for Rational Exploitation and Management of Fishery Resources. Jayyed Press. New Delhi. 
Nurnaningsih, M.F. Rahardjo, dan S. Sukimin. 2005. Pemanfaatan Makanan oleh Ikan-Ikan Dominan di Perairan Waduk Ir. H. Djuanda. Jurnal Iktiologi Indonesia. 4: (2). 61-65 p.

Odum, E.P. 1993. Fundamental of Ecology.3rd edition.Gadjah Mada University Press. Yogyakarta.

Pradini, S., M.F. Rahardjo., dan R. Kaswadji. 2001. Kebiasaan Makanan Ikan Lemuru (Sardinella lemuru) di Perairan Muncar, Banyuwangi. Jurnal Iktiologi Indonesia. 1: (1). 41-45 p.

Rahmawaty. 2013. Pengelolaan Sumber daya Perairan Waduk secara Optimal dan Terpadu. Universitas Sumatera Utara. Medan.

Royce, W.F. 1972. Introduction to The Fisheries Science. Academic Press. New York.

Sarnita, A. 1986. Perairan Umum di Indonesia sebagai salah satu Sumber daya Alam. Prosiding Seminar Perikanan Perairan Umum. Jakarta. 1 September 1986.

Sentosa, A.A., Djumanto, dan E. Setyobudi. 2008. Hubungan Panjang Berat dan Faktor Kondisi Wader Pari (Rasbora lateristriata) di Sungai Ngrancah Kabupaten Kulon Progo. Prosiding Seminar Nasional Tahunan Hasil Penelitian Perikanan dan Kelautan V. Jurusan Perikanan dan Kelautan Fakultas Pertanian UGM. Yogyakarta. 30 Juni 2008.

Sentosa, A.A. dan H. Satria. 2011. Relung Ekologi Beberapa Ikan Target Hasil Tangkapan Bubu di Sekitar Terumbu Buatan Perairan Teluk Saleh Nusa Tenggara Barat. Balai Riset Pemulihan Sumber daya Ikan. Purwakarta.

Sinaga, T.P. 1995. Bioekologi Komunitas Ikan di Sungai Banjaran Kabupaten Banyumas, Jawa Tengah. Program Institut Pertanian Bogor. Master Thesis.

Sjafei, D.S., R. Affandi \& R. Fauziah. 2004. Studi Makanan Ikan Lundu (Arius maculatus Thunberg, 1972) di Pantai Mayangan Jawa Barat. Jurnal Iktiologi Indonesia. 4(1): $15-23$.

Shirota, A. 1996.The Plankton of South Viet-Nam. Oyerseas Technical Cooperation Agency. Japan. 416 p.

Sukadi, M.F. 1996. Sistem Pengelolaan Data Penelitian dalam Mendukung Pemanfaatan Sumber daya Alam Secara Optimal. Press. Puslitbangkan No 41/1996. Serpog. 1920 November 1996.

Tresna, L.K., Y. Dhahiyat, dan T. Herawati. 2012. Kebiasaan Makanan dan Luas Relung Ikan di Hulu Sungai Cimanuk Kabupaten Garut, Jawa Barat. Jurnal Perikanan dan Kelautan. 3: (3). 163-173 p.

Zacharia, P.U. Trophodynamics and Review of Methods for Stomach Content Analysis of Fishes. Central marine Fisheries Research Institute. Kochi. 1-12 p

Wardani, A. K. (2018). Sikap Spiritual Siswa Di Smp Muhammadiyah Daarul Arqom Tulung Tahun 2017/2018. Skripsi. Surakarta: Fkip. 